\title{
Unified computable urban economic model
}

\author{
Takayuki Ueda • Morito Tsutsumi • \\ Shinichi Muto • Kiyoshi Yamasaki
}

Received: 27 August 2010 / Accepted: 24 January 2012 / Published online: 18 February 2012

(C) The Author(s) 2012

\begin{abstract}
The computable urban economic (CUE) model is a tool for analyzing real urban economies and evaluating urban polices in practice. The CUE model can output a set of variables which describe a real urban economy: a distribution of locators or activities including households and firms, a distribution of land use including residential, commercial, manufacturing, business, agricultural and other types and a distribution of land price/rent and building price/rent. The CUE model, working with transport models consistent with microeconomic theory, can also output a distribution of passenger trips aggregated by $\mathrm{OD}$, mode and path, and a distribution of freight cargo as well. Urban models that belong to the CUE model family have been developed and applied since the late 1980s. This paper first presents a general form of the CUE model, describing its mathematical forms and theoretical features. Then, the paper introduces several models in the CUE model family developed in Japan and shows that a CUE
\end{abstract}

T.Ueda Ex-Professor at The University of Tokyo Passed away on 19 September 2009 before the submission of this paper.

T. Ueda

Department of Civil Engineering, The University of Tokyo,

7-3-1 Hongo, Bunkyo-ku, Tokyo 113-8656, Japan

M. Tsutsumi $(\varangle)$

Department of Policy and Planning Sciences,

University of Tsukuba, Tsukuba, Ibaraki, Japan

e-mail: tsutsumi@sk.tsukuba.ac.jp

S. Muto

Department of Civil and Environmental Engineering,

University of Yamanashi, Kofu, Yamanashi, Japan

e-mail: smutoh@yamanashi.ac.jp

K. Yamasaki

Value Management Institute, Ltd., Tokyo, Japan

e-mail: kiyoshi_yamasaki@vmi.co.jp 
model constructed on the basis of the general form comprises the existing models. The paper compares the models with each other from the viewpoints of experiences of application, and mathematical function form, and provides clear insight into the relationship between the models.

JEL Classification $\mathrm{R} 19 \cdot \mathrm{R} 52 \cdot \mathrm{R} 13$

\section{Introduction}

"Modern urban economics owes its beginnings to the work of Alonso (1964) ... Urban economics took great strides beyond Alonso's seminal contribution and became an established field through the work of Muth (1969), Mills (1967, 1972), and others" (Anas 1982, p. 2). While these works belong to positive theory, Herbert and Stevens (1960) developed a normative theory. Fujita (1989) clarified the theoretical relations between positive and normative theories and extended them from static to dynamic theories.

Although these studies have established the theoretical foundation of modern urban economics, they deal with continuous space and take little account of application. Anas (1982) has applied a discrete choice model to residential location and provided an operational framework for urban models, which is consistent with sophisticated urban economics.

Aside from modern urban economics, developing "operational urban models" has become popular, especially through the stream of quantitative geography (e.g., Foot 1981). Among the researchers studying these urban models, Lowry (1964) has had a great impact on land-use/transport models. One of the distinguished characteristics of Lowry-type models is "quasi-dynamics." These operational models deal with discrete space, that is, zones, since most of the available data are collected by zones. The advent of the practical geographic information system (GIS) in 1970 promoted the development of operational models. In order to compare or test a land-use/transport model with another, the International Study Group on land-use/transport interaction (ISGLUTI) was set up in 1981 (Webster et al. 1988). Eleven organizations from eight countries participated in the ISGLUTI study. ISGLUTI was inherited by the Special Interest Group (SIG) of the World Conference on Transport Research Society (WCTRS). However, the land-use/transport interaction (LUTI) model still has behavioral inconsistency and systemic inconsistency, as Anas $(1982,1987)$ pointed out from the viewpoint of equilibrium in microeconomics.

The computable urban economic (CUE) model is a tool for analyzing real urban economies and evaluating urban polices in practice. The CUE model is based on standard theories in the tradition of urban economics since Alonso (1964) so that it can evaluate the urban polices consistently with welfare economics, in particular, with cost-benefit analyses.

Although Wegener (2003) has reviewed recent developments in the field of operational LUTI models, he has not considered CUE models. The CUE model can be interpreted as an advanced form of an urban model developed on the basis of an LUTI model. The CUE model is fully based on a microeconomic foundation so as to 
overcome the inconsistent features in the LUTI model. The behavior of any economic agent is explicitly formalized as utility-max or profit-max, and the interactions both at the inside and at the outside of markets are modeled as a price-adjustment mechanism or an externality.

The CUE model can output a set of variables that describe a real urban economy. The outputs in the spatial dimension are categorized into two groups. The first type is a group of location-specific variables: a distribution of locators or activities including households and firms; a distribution of land use including residential, commercial, manufacturing, business, agricultural, and other types; and a distribution of land price/rent and building price/rent. The second type is a group of flow variables: a distribution of passenger trips aggregated by origin-destination pair, by transport mode, by path, or by link and node; and a distribution of freight cargo as well as passenger trips. The CUE can output these variables by working with transport models consistently with the microeconomic theory.

The CUE model consists of many equations derived from utility-max and profit-max. It uses actual economic data to analyze real urban economies and evaluate urban polices. These features and roles are the same as those of the computable general equilibrium (CGE) model. However, Walras' law does not hold in the CUE model, while it closely does in a CGE model. A variety of models called the CGE models have been developed and applied to the evaluation of public policies such as tax reform, agreement in international trade, and subsidy allocation to industrial sectors. The CGE model outputs equilibrium price/quantity in all markets that are mutually consistent for cases both with and without a policy. The CUE model can contribute to the practical impact analysis for urban policies as well as the CGE model does in the other domains of economic policy.

After the ISGLUTI study, many land-use/transport models in Japan have been developed employing the idea by Anas (1982). Urban models in the family of the CUE model have been developed and applied in Japan since the late 1980s. They have been successful in analyzing impacts of urban policies in practice.

This paper first aims at presenting a general and standard form of the CUE model. The mathematical form of the CUE model and its theoretical features are described. The behavior of each economic agent including consumption, production, and choice of location is formalized based on the utility-maximizing or profitmaximizing principle. Demand and supply in land or building markets are balanced in all zones. An equilibrium state of an urban economy is defined as a solution of a system of equations and is rewritten as a solution of an equivalent mathematical programming.

The paper then introduces several models in the CUE model family developed and applied in Japan. The CUE model consisting of the above-mentioned general and standard form is a unified model of these models. More precisely, each of the models is a special case of the general model with the specification of indirect utility, profit, demand, and supply functions, which reflect some special interests in the applications of urban policies in impact analysis. The paper compares the models with each other from the viewpoints of experiences of application, and mathematical function form, and provides clear insight into the relationship between the models. 


\section{General form of computable urban economic model}

\subsection{General form of the CUE model}

In a variety of urban models, the CUE model is characterized by a microeconomic foundation and by a spatial equilibrium on the basis of urban economics. Each economic agent demands or supplies land, building, transport service, and other goods at a location of choice. A footloose economic agent, called a locator in this paper, chooses the location where the utility or profit is the highest among all locations in an urban system. The land and building rent at each location (zone) that attains a demand-supply balance at the location is determined simultaneously. When an urban economy is in equilibrium, the attained level of utility or profit for each type of locators is equalized among locations (zones). The CUE model can simulate a real urban economy as well as other urban models. However, it differs from them in that its outputs are fully consistent with the benefit indicators used in practical cost-benefit analyses.

\subsection{Major assumptions}

The CUE model has certain major assumptions listed below.

\subsubsection{Discrete representation of space}

The spatial coverage of an urban economy is divided into zones. A zone is an area that has homogeneous geographical and economic features. A label for a zone therefore indicates a location. There exist a land market and a building market in each zone.

\subsubsection{Locators}

A footloose economic agent in the model is called a locator. The locator can choose a location where she/he consumes or produces goods. Locators are categorized into several types. The total number of locators for each type is exogenous in the model. The model therefore describes an economy of a closed city on the basis of urban economics.

\subsubsection{Zone-specific land/building markets and suppliers}

In each zone, there exist a land market and a building market in which a unique equilibrium price is determined. A supplier of a building in each zone is a representative developer specific to the zone. A supplier in the land market in each zone is a representative absentee landowner. Each landowner provides the land space that has homogeneous geographical and economic features. The type of land owner is thus a label for the type of land.

The suppliers behave so as to maximize their profits. When the revenue from land or building supply has randomness, the suppliers allocate land or building space by a stochastic choice. 


\subsubsection{Location choice}

Any locator demands building space so as to maximize its utility or profit in any zone. Given a distribution of the level of indirect utility or profit among all zones, the locator chooses the zone where she/he can enjoy the highest level of indirect utility or profit. Since the distribution of the level of indirect utility or profit includes randomness, the location choice behavior is stochastic. The logit model is employed to represent a discrete choice of zone for the locator to locate.

\subsubsection{Equilibrium}

An equilibrium state of an urban economy is defined with two conditions. One is that any locator has no incentive to relocate or to change its location. In other words, the locator cannot enjoy a higher level of indirect utility or profit in other zones than in the present zone. The other condition is that demand-supply balance or clearing in land and building markets in any zone is attained simultaneously.

\subsection{Formalizing the CUE model}

Although some important symbols are defined below, a notational glossary for the CUE model is presented in the "Appendix" for the readers' convenience.

\subsubsection{Locator's demand for building space}

A locator maximizes her/his utility by choosing the consumption of building/land space and other goods with an income constraint at a chosen location. If the locator is a firm, the utility is replaced with profit. The locator's maximization of utility or profit derives individual demand for building/land space. The demand of the locator $k$ locating in the zone $i$ for the building space is denoted by $q_{i k}=q\left(R_{i}, e_{i}, E_{i}, \alpha_{k}, Y_{k}\right)$, which is a function of the income $Y_{k}$ and the building rent $R_{i}$.

A particular form of the individual demand function $q_{i k}=q\left(R_{i}, e_{i}, E_{i}, \alpha_{k}, Y_{k}\right)$ can be derived from the corresponding indirect utility or profit function $V_{k i}=$ $V\left(R_{i}, e_{i}, E_{i}, \alpha_{k}, Y_{k}\right)$, as proved in the case of Roy's identity or Hotelling's lemma in a standard textbook of microeconomics like Vairan (1992). We therefore have to specify the functions $q_{i k}=q\left(R_{i}, e_{i}, E_{i}, \alpha_{k}, Y_{k}\right)$ and $V_{k i}=V\left(R_{i}, e_{i}, E_{i}, \alpha_{k}, Y_{k}\right)$ consistently with each other in each application of the model. The endogenous geographical/economic features $e_{i}=e_{i}(N)$ and other exogenous variables $E_{i}, \alpha_{k}$ are included in the functions.

\subsubsection{Location choice behavior}

The indirect utility or profit that a locator can attain at a location or in a zone by optimizing individual building space is the attractiveness of the zone for the locator. The location choice among zones is formalized with the logit model. The logit model is derived from the following maximization problem as Miyagi (1986) and Oppenheim (1995) showed. 


$$
\begin{gathered}
S\left(V_{k}, \theta_{k}\right)=\max _{a_{k}} \sum_{i \in \mathbf{I}_{k}}\left\{a_{k i} V_{k i}-\left(\frac{1}{\theta_{k}}\right) a_{k i}\left(\ln a_{k i}-1\right)\right\}, \\
\text { s.t. } \sum_{i \in \mathbf{I}_{k}} a_{k i}=1, \\
S\left(V_{k}, \theta_{k}\right)=\left(\frac{1}{\theta_{k}}\right) \ln \left\{\sum_{i \in \mathbf{I}_{k}} \exp \left(\theta_{k} V_{k i}\right)\right\}, \\
\text { and } \quad a_{k i}\left(V_{k i}, \theta_{k}\right)=\frac{\exp \left(\theta_{k} V_{k i}\right)}{\sum_{i^{\prime} \in \mathbf{I}_{k}} \exp \left(\theta_{k} V_{k i^{\prime}}\right)} .
\end{gathered}
$$

The log-sum function in Eq. (2a), which is the maximized value obtained by the programming in Eq. (1a, 1b), is the expected value of the highest attractiveness among zones. This is a welfare measure for each type of locators.

Deterministic location choice on the basis of urban economics is a special case of Eq. (1a, 1b) where $\theta_{k}$ is positive infinite and we can ignore the so-called entropy term $a_{k i}\left(\ln a_{k i}-1\right)$ on the right-hand side.

\subsubsection{Demand for land and supply of building/land space}

An aggregate supply for building space in each zone is derived from the profit of a representative developer for the zone by using Hotelling's lemma. The building supply in zone $i, Q\left(R_{i}, P_{i}, Z_{i}, \beta\right)$, is derived from the profit $\pi^{D}\left(R_{i}, P_{i}, Z_{i}, \beta\right)$ as,

$$
\frac{\partial \pi^{D}\left(R_{i}, P_{i}, Z_{i}, \beta\right)}{\partial R_{i}}=Q\left(R_{i}, P_{i}, Z_{i}, \beta\right) .
$$

Land space is an input for the production of building in the CUE model. An aggregate demand for land space in each zone is derived from the profit of a representative developer in the zone. The land demand in zone $i, L^{D}\left(R_{i}, P_{i}, Z_{i}, \beta\right)$, is derived from the profit $\pi^{D}\left(R_{i}, P_{i}, Z_{i}, \beta\right)$ as,

$$
\frac{\partial \pi^{D}\left(R_{i}, P_{i}, Z_{i}, \beta\right)}{\partial P_{i}}=-L_{i}^{D}\left(R_{i}, P_{i}, Z_{i}, \beta\right) .
$$

In the same manner as the supply for building, an aggregate supply for land space in each zone is derived from the profit of a landowner for the zone. The land supply in zone $i, L_{i}^{S}\left(P_{m}, W_{m}, \gamma\right)$, is derived from the profit $\pi^{L}\left(P_{m}, W_{m}, \gamma\right)$ as,

$$
\frac{\partial \pi^{L}\left(P_{m}, W_{m}, \gamma\right)}{\partial P_{i}}=L_{i}^{S}\left(P_{m}, W_{m}, \gamma\right) .
$$




\subsubsection{Equilibrium}

An equilibrium state of an urban economy that the CUE model describes is defined with the conditions including the distribution of locators among zones, the demandsupply balancing of the building space in each zone, and the demand-supply balancing of the land space in each zone. They are formalized as follows:

Distribution of locators among zones:

$$
\begin{aligned}
N_{k i} & =N_{k T} a_{k i} \text { for all } i \in\{1, \ldots, I\} \text { and for all } k \in\{1, \ldots, K\}, \\
a_{k i} & =\frac{\exp \left(\theta_{k} V\left(R_{i}, e_{i}(N), E_{i}, \alpha_{k}, Y_{k}\right)\right)}{\sum_{i^{\prime} \in \mathbf{I}_{k}} \exp \left(\theta_{k} V\left(R_{i^{\prime}}, e_{i^{\prime}}(N), E_{i^{\prime}}, \alpha_{k}, Y_{k}\right)\right)},
\end{aligned}
$$

Demand-supply balancing of building space:

$$
\begin{aligned}
& -\sum_{k \in \mathbf{K}} N_{k T} a\left(V_{k 1}(\cdot) \ldots, V_{k I}(\cdot), \theta_{k} ; i\right) q\left(R_{i}, e_{i}, E_{i}, \alpha_{k}, Y_{k}\right)+Q\left(R_{i}, P_{i}, Z_{i}, \beta\right)=0 \\
& \quad \text { for all } i \in\{1, \ldots, I\}
\end{aligned}
$$

Demand-supply balancing of land space:

$$
L_{i}^{S}\left(P_{m}, W_{m}, \gamma\right)-L^{D}\left(R_{i}, P_{i}, Z_{i}, \beta\right)=0 \text { for all } i \in\{1, \ldots, I\} \quad \text { and } m \in\{1, \ldots, M\} .
$$

Note that $P_{m}$ is a vector, while $P_{i}$ is scalar.

\section{CUE models developed in Japan}

\subsection{List of models}

In Japan, there are several types of models classified as the CUE model. They have been developed by Japanese urban modelers and applied to urban areas in Japan. Here, we compare the models from various viewpoints. The models are listed below and in Table 1.

Double-Side Discrete Choice Model (DSDC Model)

Discrete-Continuous Land Demand Model (DCLD Model)

Random Utility/Rent-Bidding Analysis Model (RURBAN Model)

Building Demand-Supply Balancing Model (BDSB Model)

Continuous-Discrete Land Supply Model (CDLS Model)

Neo-Computable Urban Economic Model Family (NCUE Model Family)

CUE for River Improvement Project (R-CUE)

CUE for Gifu Urban Area (G-CUE)

CUE by Value Management Institute (VM-CUE)

Double-Side Discrete Choice Model (DSDC model) is characterized with the feature that not only locator's choice of a location but also the allocation of land to each locator type is formalized by the logit model. Both the locator side (demand side of 


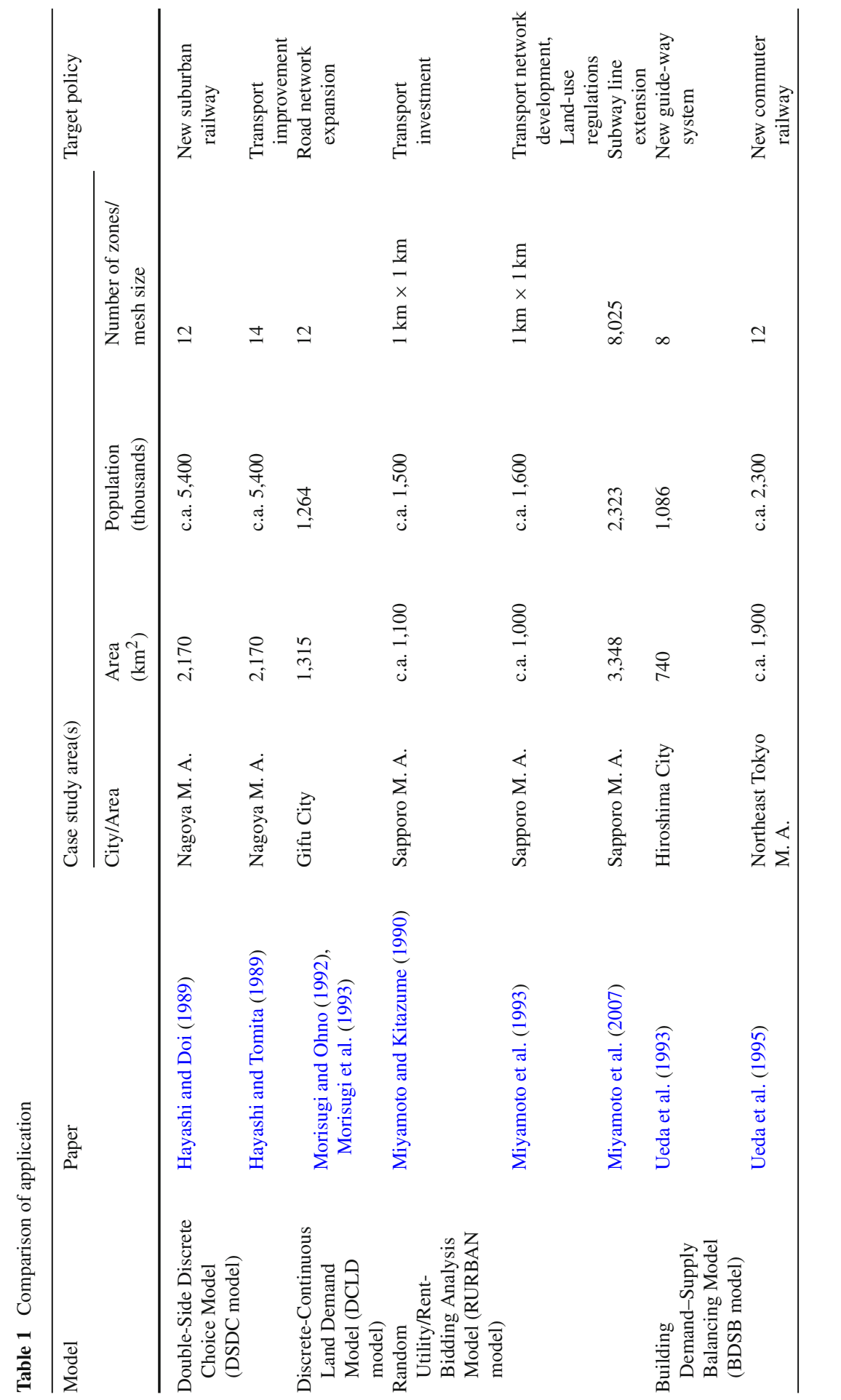




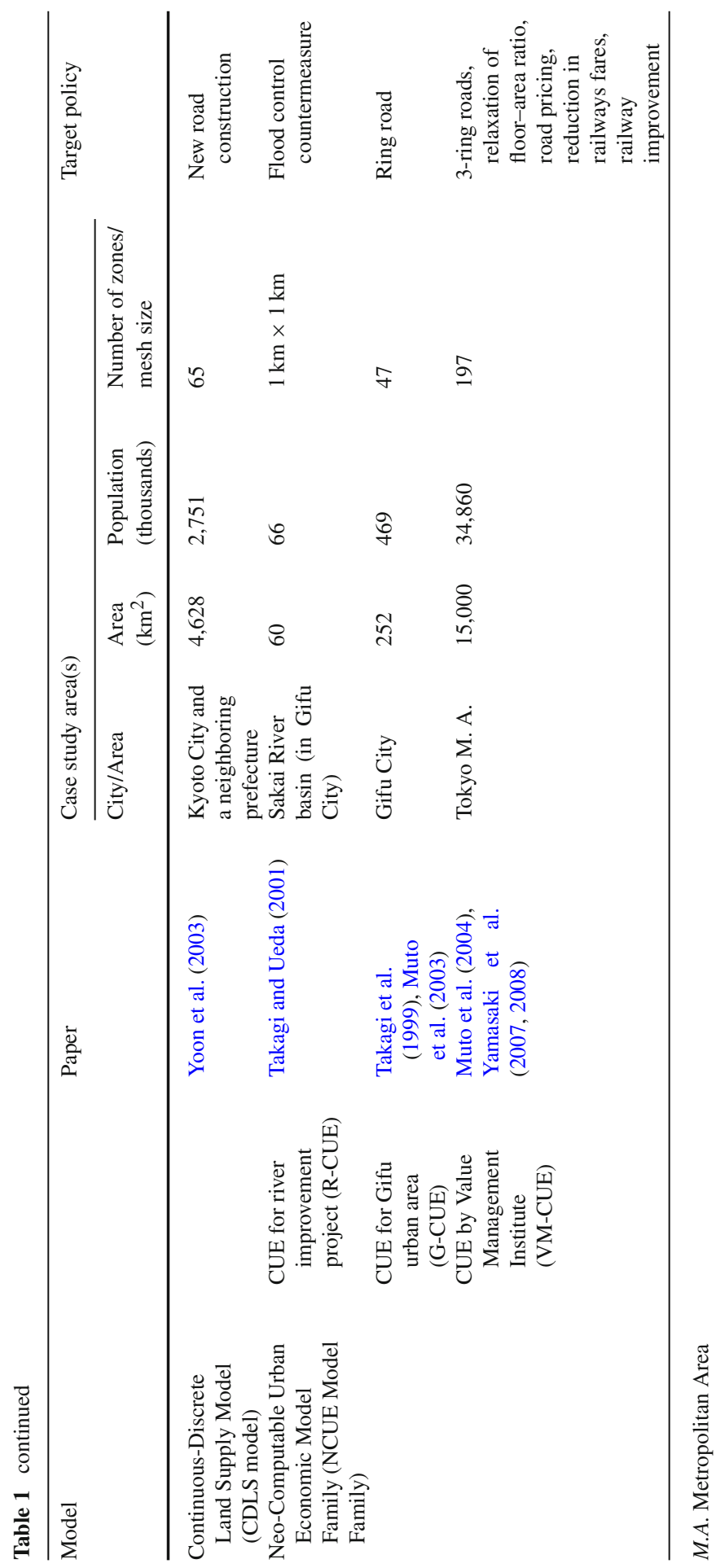


building space) and the landowner side (supply side of land) are thus simultaneously modeled by the discrete choice model.

Discrete-Continuous Land Demand Model (DCLD model) has been modeled such that a locator first chooses a location as a discrete zone and then determines a demand for land (building space) as a continuous variable. The two-level choice in this approach is called the Discrete-Continuous Choice. Since the model has simplified the supply side of land so as to mainly focus on the demand side, the model is characterized by the Discrete-Continuous Land Demand.

Random Utility/Rent-Bidding Analysis Model (RURBAN model) was simultaneously based on both the random utility theory and the random bidding theory in its original formulation. The original formulation contained an inconsistency with price mechanism in market equilibrium. This paper therefore reformulates the RURBAN model so as to solve the inconsistency.

Building Demand-Supply Balancing Model (BDSB model) has been motivated by formalizing the building market explicitly. The modeling of the building market is the heart of analysis for the emergence of high-raised buildings particularly in a city center. The model has uniquely formalized the building market.

Continuous-Discrete Land Supply Model (CDLS model) is characterized by the two-level choice structure in land supply. The model has assumed that the landowner first determines the total amount of land supply as a continuous variable and then allocates the amount to each type of locators by a discrete choice (logit model). The model is very unique and represents the Continuous-Discrete choice behavior of a landowner.

Neo-Computable Urban Economic Model Family (NCUE Model Family) consists of the CUE models that we have developed. Member models in the family have been applied to a variety of urban policies including transport, land-use regulation, urban redevelopment, residential area development, and business district reform. Such a variety of applications has required each member model in the family to work together with other simulation models such as the flood simulation model, $\mathrm{CO}_{2}$ emission model, or transport pricing model.

\subsection{Applications to impact analysis of urban policies}

Table 1 compares the models from the point of application to practical policy analysis. The models have been applied to impact analysis of urban policies in medium-sized cities except VM-CUE, which has been applied to the Tokyo Metropolitan Area.

The policies targeted in the impact analysis are not only the transport network development plans and land-use regulations at a regional master plan level but also particular projects and policies such as the new suburban railway, new guide-way system, new commuter railway, new road investment, flood control countermeasure, ring road development, deregulation of floor-area ratio, road pricing, and railways pricing. The CUE models have been applied to the impact analysis of a large variety of policies.

The impacts of a policy are represented as changes in distribution of locators, building rents, land rents, trips, and environmental emissions. The distribution of trips can 
be outputted by transport network models interactively working with the CUE model. The environmental emissions are calculated by engineering models or material flow models combined with the CUE model. The impact analysis in these years inevitably has to evaluate the reduction in greenhouse gas emission, particularly $\mathrm{CO}_{2}$ emission. The VM-CUE in the NCUE family model has targeted the reduction in $\mathrm{CO}_{2}$ emission from transport sectors by a variety of urban policies in the Tokyo Metropolitan Area.

\section{Unified computable urban economic model}

The previous section introduced several models in the CUE model family developed and applied in Japan. This section proves that the CUE model consisting of the general and standard form, described in Sect. 2, is a unified model of these models. More precisely, each of the models is a special case of the general model with the specification of indirect utility, profit, demand, and supply functions, which reflect some special interests in the applications to the impact analysis of urban policies. In order to provide a clear insight into the relationship between these models, we compare each model with others from the viewpoints of mathematical function form and programmability of equilibrium.

\subsection{Zone setting}

Table 2 presents a comparison of the style of model zone setting.

There are two groups from the point of zone setting.

\subsubsection{Zone defined for each pair of locator type and land type}

A zone is defined for a pair of locator type $k \in \mathbf{K}\{1, \ldots, K\}$ and land type $m \in$ $\mathbf{M}\{1, \ldots, M\}$. A label of zone $i \in \mathbf{I}$ means $i=(k, m) \in\{(k, 1), \ldots,(K, M)\}$. A locator in type $k \in \mathbf{K}$ can choose only the zones belonging to the subset $\mathbf{I}_{k}=\{(k, 1), \ldots,(k, M)\} \subseteq \mathbf{I}$.

Table 2 Comparison of zone setting

\begin{tabular}{|c|c|c|c|}
\hline Model & Label for zone & $\begin{array}{l}\text { Label of zone for } \\
\text { locator to locate }\end{array}$ & $\begin{array}{l}\text { Label of zone for } \\
\text { landowner to } \\
\text { supply }\end{array}$ \\
\hline General form & $i \in \mathbf{I}$ & $\mathbf{I}_{k}$ & $\mathbf{I}_{m}$ \\
\hline DSDC model & $\begin{array}{l}i=(k, m) \\
\in \mathbf{I}=\{(k, 1), \ldots,(K, M)\}\end{array}$ & $\mathbf{I}_{k}=\{(k, 1), \ldots,(k, M)\}$ & $\mathbf{I}_{m}=\{(1, m), \ldots,(K, m)\}$ \\
\hline DCLD model & $i=m \in \mathbf{I}=\{1, \ldots, M\}$ & $\mathbf{I}_{k}=\{1, \ldots, M\}$ & $\mathbf{I}_{m}=\{m\}$ \\
\hline RURBAN model & $\begin{array}{l}i=(k, m) \\
\in \mathbf{I}=\{(k, 1), \ldots,(K, M)\}\end{array}$ & $\mathbf{I}_{k}=\{(k, 1), \ldots,(k, M)\}$ & $\mathbf{I}_{m}=\{(1, m), \ldots,(K, m)\}$ \\
\hline BDSB model & $i=m \in \mathbf{I}=\{1, \ldots, M\}$ & $\mathbf{I}_{k}=\{1, \ldots, M\}$ & $\mathbf{I}_{m}=\{m\}$ \\
\hline CDLS model & $\begin{array}{l}i=(k, m) \\
\in \mathbf{I}=\{(k, 1), \ldots,(K, M)\}\end{array}$ & $\mathbf{I}_{k}=\{(k, 1), \ldots,(k, M)\}$ & $\mathbf{I}_{m}=\{(1, m), \ldots,(K, m)\}$ \\
\hline $\begin{array}{l}\text { NCUE model } \\
\text { family }\end{array}$ & $i=m \in \mathbf{I}=\{1, \ldots, M\}$ & $\mathbf{I}_{k}=\{1, \ldots, M\}$ & $\mathbf{I}_{m}=\{m\}$ \\
\hline
\end{tabular}


An amount of land in type $m \in \mathbf{M}$ can be supplied or allocated to the zones belonging to $\mathbf{I}_{m}=\{(1, m), \ldots,(K, m)\}$.

The DSCE model, RURBAN model, and CDLS model employ this style of zone setting.

\subsubsection{Zone defined for each land type}

A zone is defined for each land type $m \in \mathbf{M}\{1, \ldots, M\}$. A label of zone means $i=m \in$ $\{1, \ldots, M\}$. Since a locator in any type $k \in \mathbf{K}$ can choose any zone in an urban economy, the choice set of zones for a locator to locate is written as $\mathbf{I}_{k}=\{1, \ldots, M\}=\mathbf{I}$. A landowner in type $m \in \mathbf{M}$ can supply the land only to the zone labeled by $i=m \in \mathbf{M}=$ $\{1, \ldots, M\}$. Further, the set of zones for the landowner to supply is $\mathbf{I}_{m}=\{m\} \subseteq \mathbf{I}$. In the zone setting, locators in different types can locate in the same zone simultaneously.

The DCLD model, BDSB model, and NCUE model family employ this style of zone setting.

\subsection{Location attractiveness function and individual demand function for building}

The location attractiveness function and individual demand function for building space are compared in the second and third columns of Table 3, respectively.

\subsubsection{Price-elastic demand}

The log-linear indirect utility function $V_{k i}=\phi\left(e_{i}, E_{i}, \alpha_{k}\right)-\rho_{k} \ln R_{i}+\varphi_{k} \ln Y_{k}$ must yield the individual demand function for building space $q_{i k}=\rho_{k} \frac{Y_{k}}{R_{i}}$, as employed in the DCLD model, RURBAN model, and NCUE model family. In contrast, the BDSB model has transformed the linear function of individual demand for building space $q_{i k}=a-b R_{i}$ into the indirect utility function as an integral $\int_{R_{i}}^{\bar{R}}(a-b s) \mathrm{d} s$. The integral indicates the consumer's surplus; then, the indirect utility is measured in monetary terms.

\subsubsection{Price-inelastic demand}

The DSDC model and CDLS model have treated an individual demand for building space as an exogenous parameter in static equilibrium. If the demand is price-inelastic in a real urban economy, the practical analysis will be simplified.

\subsection{Aggregate supply for building and demand for land}

Aggregate supply for building and demand for land are compared in the fourth and fifth columns of Table 3 , respectively. 


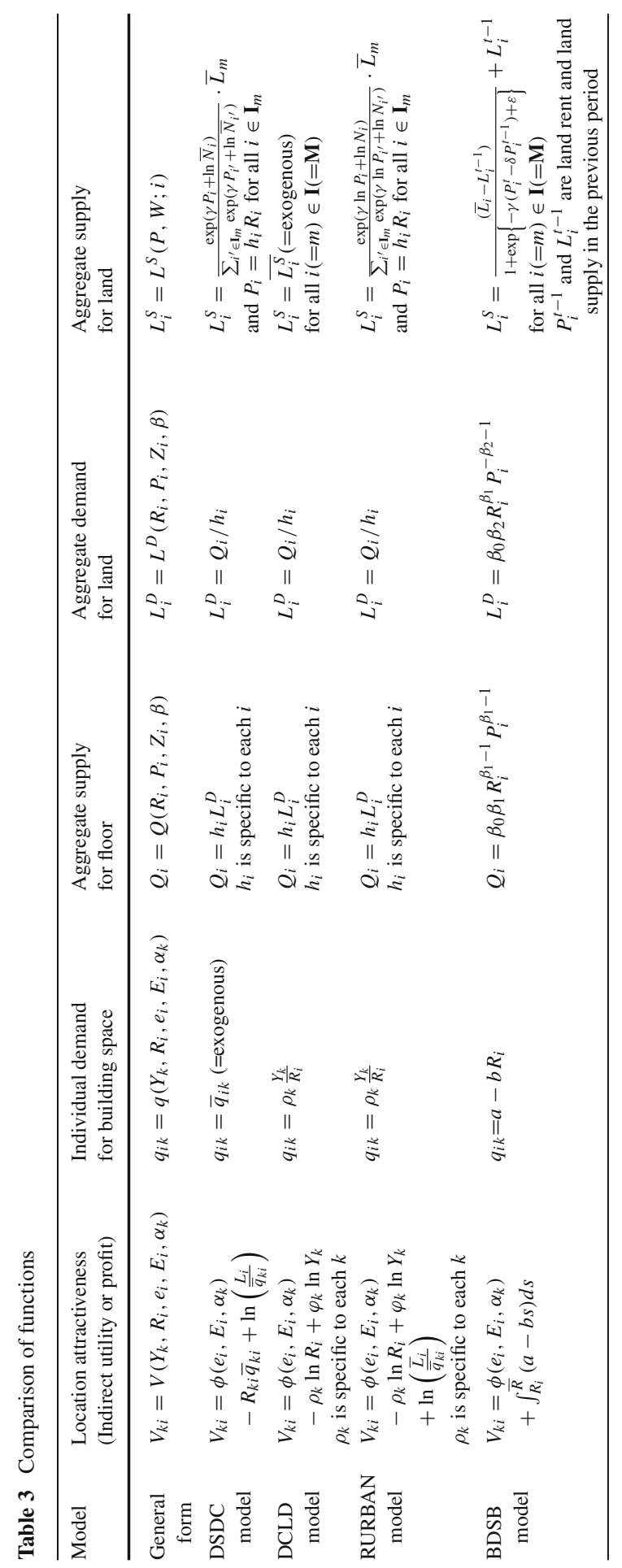




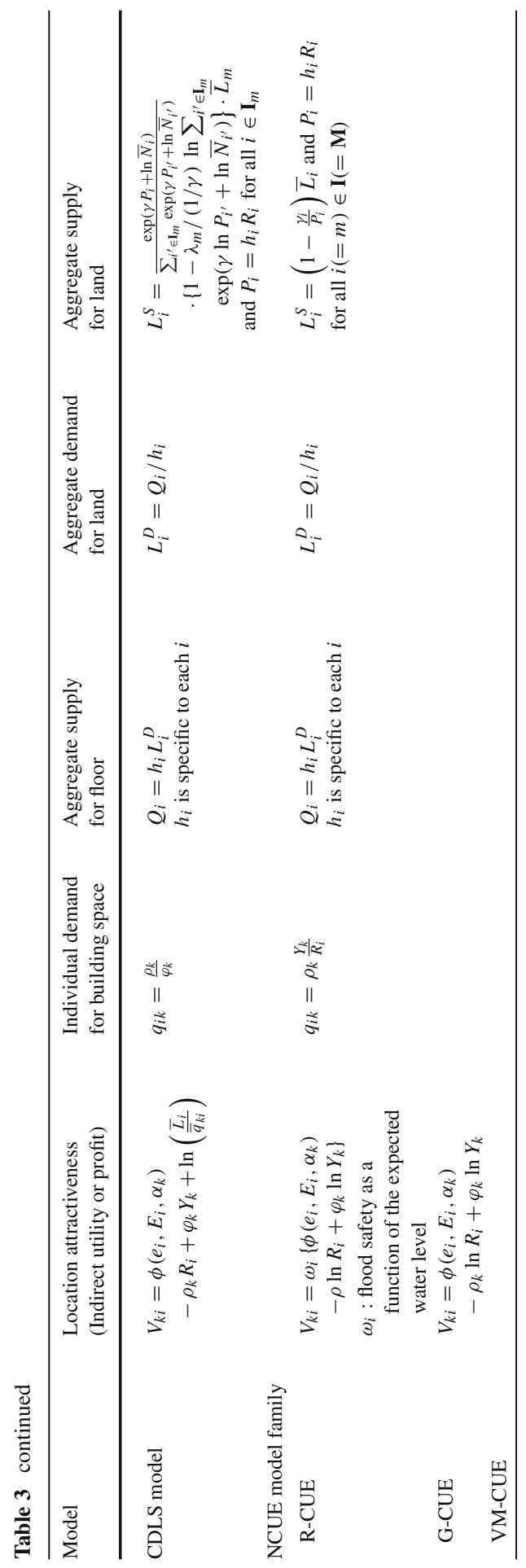




\subsubsection{Endogenous building supply}

Only the BDSB model has described the endogenous supply of building space by a representative developer for each zone. The land is an input factor for producing building space. The supply function for a building $Q_{i}=\beta_{0} \beta_{1} R_{i}^{\beta_{1}-1} P_{i}^{\beta_{1}-1}$ and the factor demand function for land $L_{i}^{D}=\beta_{0} \beta_{2} R_{i}^{\beta_{1}} P_{i}^{-\beta_{2}-1}$ are derived from the developer's profit maximization with the Cobb-Douglas production function $Q=\beta_{0}\left(L^{D}\right)^{\beta_{1}}(\mathrm{Cap})^{1-\beta_{1}}$, where Cap denotes a capital input for producing building space. The capital rent is normalized to be one.

\subsubsection{Exogenous building supply}

In other models in the CUE model family, it is assumed that the aggregate supply of building space in any zone $Q_{i}$ is proportional to the aggregate land supply $L_{i}^{D}$. Then, they are described as $Q_{i}=h_{i} L_{i}^{D}$ or $L_{i}^{D}=Q_{i} / h_{i}$, where the coefficient $h_{i}$ denotes a floor volume ratio in zone $i \in \mathrm{I}$. This approach is applicable in practice if the floor volume ratio reaches an upper limit in any zone. At equilibrium, the zero developer's profit holds as $R_{i} Q_{i}-P_{i} L_{i}^{D}=\left(h_{i} R_{i}-P_{i}\right) L_{i}^{D}=0$. The building rent and the land rent in any zone thus satisfy $h_{i} R_{i}=P_{i}$.

\subsection{Aggregate supply for land}

Aggregate supply functions for land are compared in the sixth column of Table 3.

\subsubsection{Exogenous land supply}

The simplest modeling of the aggregate supply of land is that the supply is given as an exogenous variable to each zone $L_{i}^{S}=\overline{L_{i}^{S}}$. Only the DCLD model employs this modeling.

\subsubsection{Discrete choice in land supply}

The logit model is employed not only to describe the location choice of locators but also to formalize the allocation of land to zones. The DSDC model and the RURBAN model have modeled a repetitive landowner in type $m \in \mathbf{M}$ who allocates the total amount of land $\bar{L}_{m}$ to zones labeled by $i \in \mathbf{I}_{m}$. The probability or the share of land supply to the zone $L_{i}^{S}\left(i \in \mathbf{I}_{m}\right)$ to the total amount $\bar{L}_{m}$ is stated by the $\operatorname{logit} \operatorname{model} \exp \left(\gamma P_{i}+\right.$ $\left.\ln \bar{N}_{i}\right) / \sum_{i^{\prime} \in \mathbf{I}_{m}} \exp \left(\gamma P_{i^{\prime}}+\ln \bar{N}_{i^{\prime}}\right)$ or $\exp \left(\gamma \ln P_{i}+\ln N_{i^{\prime}}\right) / \sum_{i^{\prime} \in \mathbf{I}_{m}} \exp \left(\gamma \ln P_{i}+\ln N_{i^{\prime}}\right)$, where $\gamma$ is the parameter that governs the landowner's preference.

The CDLS model also employs the logit model for the allocation of land to zones but assumes that the total amount of land $L^{S}\left(\Omega_{i}\right)=\left(1-\frac{\lambda_{m}}{\Omega_{i}}\right) \cdot \bar{L}_{m}$ is endogenous as a function of the expected maximum land rent in terms of the log-sum form $\Omega_{i}=\left(\frac{1}{\gamma}\right) \ln \sum_{i^{\prime} \in \mathbf{I}_{m}} \exp \left(\gamma \ln P_{i^{\prime}}+\ln \bar{N}_{i^{\prime}}\right)$. 


\subsubsection{Land supply only to the zone for each land type}

Since the BDSB model and NCUE model family have defined a zone for each land type, the land in type $m \in \mathbf{M}$ is supplied only to the zone $i \in \mathbf{I}_{m}=\{m\}$. The aggregate land supply is a function of the total available land $\bar{L}_{m}$ and the land rent in the zone $P_{i}^{t}$.

\section{Concluding remarks}

This paper has presented a unified CUE model that comprises several CUE models that have been developed and applied in Japan for the impact analysis of urban policies including transport policies, land-use regulations, and infrastructure investment projects.

The paper has compared each model with others with respect to application and mathematical function form; the results of these comparisons would definitely contribute to future model development. Since each model in the family of the CUE model is a special case of the general form, a combination of parts employed from different models can be a new member of the family. In other words, some parts of a member model can be replaced with corresponding parts of the other member models in the CUE model family. Particularly, the aggregate land supply function can be used interchangeably among the models in the CUE model family.

There still exist a considerable number of tasks for further development of the models in the family of the CUE model. We have to be engaged in these tasks.

The most critical one is the development of an efficient algorithm for searching a solution. The models are described as a large system of equations or inequalities to be solved. The computation is so tough that it takes more than an hour to obtain a solution in the application to a large urban area like Tokyo. When the models are working interactively with a transport network model for traffic assignment, the computation time is more critical in practical applications (e.g., Kim 1989). Although computer hardware would advance continuously, a great effort for developing an efficient algorithm for a quick searching is demanded.

Another task to be mentioned here is the development of more sophisticated techniques for parameter estimation from the viewpoint of statistics. The so-called calibration method has been widely used for parameter setting, which is similar to CGE (e.g., Shoven and Whalley 1992). However, since the calibration method is a deterministic approach, no statistical test can be used for model specification. Thus, there has been considerable criticism against it although the method remains widely used for its advantages.

\section{Appendix A: Notational glossary for CUE model}

Variables and functions necessary for describing a general mathematical form of the CUE model are listed here. They are distinguished in the way provided by Anas and Liu (2007). 
Labels and sets

$i \in\{1, \ldots, I\}:$ label for a zone.

$k \in \mathbf{K}\{1, \ldots, K\}$ : label for a locator type.

$m \in \mathbf{M}\{1, \ldots, M\}$ : label for a landowner or a type of land.

$(i \in) \mathbf{I}_{m}$ : set of labels for the zones that a landowner $m$ provides her/his land.

$$
\bigcup_{m} \mathbf{I}_{m}=\{1, \ldots, I\} \text {, and } \mathbf{I}_{m} \bigcap \mathbf{I}_{m^{\prime}}=\varnothing \text { for all } m \neq m
$$

$(i \in) \mathbf{I}_{k}$ : set of labels for the zones that a locator in type $k$ can choose to locate and

$$
\bigcup_{k} \mathbf{I}_{k}=\{1, \ldots, I\} .
$$

Exogenous variables and vectors

$N_{k i} \in \mathbf{R}_{+}$: number of locators in type $k$ locating in zone $i$.

$N_{k}=\left[N_{k 1}, \ldots, N_{k I}\right] \in \mathbf{R}_{+}^{I}:$ vector associated with $N_{k i}$.

$N_{k T}=\sum_{i \in \mathbf{I}} N_{k i} \in \mathbf{R}_{+}:$total number of locators in type $k$.

$N=\left[N_{1}, \ldots, N_{K}\right] \in \mathbf{R}_{+}^{K \times I}:$ vector associated with the vector $N_{k}$.

$L_{m} \in \mathbf{R}_{+}$: amount of land owned by a landowner in type $m$ or the available amount of a land type $m$.

$E_{i} \in \mathbf{R}^{G^{\prime}}: G^{\prime}$-dimensional vector associated with the exogenous geographical/economic features or exogenous attributes of zone $i$.

$E=\left[E_{1}, \ldots, E_{I}\right]:$ vector associated with $E_{i}$.

Endogenous variables and vectors

$R_{i} \in \mathbf{R}_{+}$: building (floor) rent in zone $i$.

$R=\left[R_{1}, \ldots, R_{I}\right] \in \mathbf{R}_{+}^{I}$ : vector associated with $R_{i}$.

$P_{i} \in \mathbf{R}_{+}$: land rent in zone $i$.

$P=\left[P_{1}, \ldots, P_{I}\right] \in \mathbf{R}_{+}^{I}$ : vector associated with $P_{i}$.

$P_{m}$ : vector associated with the land rent in zone $i$, which belongs to the set $\mathbf{I}_{m}$.

$Q_{i} \in \mathbf{R}_{+}$: aggregate building supply in zone $i$.

$Q=\left[Q_{1}, \ldots, Q_{I}\right] \in \mathbf{R}_{+}^{I}$ : vector associated with $Q_{i} \in \mathbf{R}_{+}$.

$L_{i}^{D} \in \mathbf{R}_{+}$: aggregate land demand in zone $i$.

$L^{D}=\left[L_{1}^{D}, \ldots, L_{I}^{D}\right] \in \mathbf{R}_{+}^{I}$ vector associated with $L_{i}^{D}$.

$L_{i}^{S} \in \mathbf{R}_{+}$: aggregate land supply in zone $i$.

$L^{S}=\left[L_{1}^{S}, \ldots, L_{I}^{S}\right] \in \mathbf{R}_{+}^{I}$ : vector associated with $L_{i}^{S}$.

$e_{i}=e_{i}(N) \in \mathbf{R}^{G}: G$-dimensional vector associated with the endogenous geographical/economic features or endogenous attributes of zone $i$, which is dependent on the distribution of locators denoted by the vector $N$ so as to indicate externality. $e=\left[e_{1}, \ldots, e_{I}\right]$ : vector associated with $e_{i}$. 
Locators

\section{Parameters}

$\alpha_{k}=\left[\alpha_{k 1}, \ldots, \alpha_{k H^{\prime}}\right]: H^{\prime}$-dimensional vector associated with parameters governing the attractiveness of a zone for the locator in type $k$.

$\alpha=\left[\alpha_{1}, \ldots, \alpha_{K}\right]$ : vector associated with $\alpha_{k}$.

$\theta_{k}$ : parameter in the logit model for location choice of the locator $k$.

$\theta=\left[\theta_{1}, \ldots, \theta_{K}\right]:$ vector associated with $\theta_{k}$.

\section{Intermediate variables}

$V_{k i}=V\left(R_{i}, e_{i}, E_{i}, \alpha_{k}, Y_{k}\right):$ location attractiveness (the indirect utility or profit) which a locator in type $k$ can enjoy in $i$.

$V_{k}=\left[V_{k 1}, \ldots, V_{k I}\right] \in \mathbf{R}_{+}^{I}$ : vector associated with $V_{k i}$.

$V=\left[V_{1}, \ldots, V_{K}\right] \in \mathbf{R}_{+}^{K \times I}$ : vector associated with $V_{k}$.

$q_{i k}=q\left(R_{i}, e_{i}, E_{i}, \alpha_{k}, Y_{k}\right):$ individual floor apace demand of the locator $k$ in zone $i$.

$a_{k i}=\frac{N_{k i}}{N_{k T}}=a_{k i}\left(V_{k}, \theta_{k} ; i\right):$ probability that the locator in type $k$ chooses the zone $i$.

$S\left(V_{k}, \theta_{k}\right): \log$-sum function of the locator $k$ in the logit model for location choice.

\section{Exogenous variables}

$Y_{k}$ : income level of the locator type $k$ (to be ignored if the locator is not a household). $M I V_{k}=\operatorname{MIV}\left(R_{i}, e_{i}, E_{i}, \alpha_{k}, Y\right):$ marginal utility of income of the locator $k$ in zone $i\left(M I V\left(R_{i}, e_{i}, E_{i}, \alpha_{k}, Y\right)=1\right.$ if the locator is not a household).

\section{Developer}

\section{Parameters}

$\beta=\left[\beta_{1}, \ldots, \beta_{H^{\prime \prime}}\right]$ : vector associated with parameters governing a developer's technology.

$Z_{i}: H^{\prime \prime}$-dimensional vector associated with exogenous parameters governing the aggregate building supply in zone $i$.

$Z=\left[Z_{1}, \ldots, Z_{I}\right]$ : vector associated with $Z_{i}$.

\section{Intermediate variables}

$\pi_{i}^{D}=\pi^{D}\left(R_{i}, P_{i}, Z_{i}, \beta\right):$ profit of the developer in zone $i$. 
Landowner

\section{Parameters}

$W_{m}: H^{\prime \prime \prime}$-dimensional vector associated with exogenous parameters governing the aggregate land supply in zone $i$.

$W=\left[W_{1}, \ldots, W_{M}\right]$ : vector associated with $W_{m}$.

\section{Intermediate variables}

$\pi_{m}^{L}=\pi^{L}\left(P_{m}, W_{m}, \gamma\right)$ : profit of a landowner in type $m$.

In the above notations, $\mathbf{R}$ is a set of real numbers, and $\mathbf{R}_{+}$is a set of non-negative real numbers. $\mathbf{R}^{n}$ denotes an $n$-dimensional Euclidean space.

\section{Appendix B: Reformulation of the RURBAN model}

Since the RURBAN model was simultaneously based on both the random utility theory and the random bidding theory in its original formulation, the original formulation contained an inconsistency with the price mechanism in market equilibrium. We have reformulated the RURBAN model in this paper. This appendix explains the inconsistency in the original formulation.

The zone settings in the RURBAN model are $i=(k, m) \in \mathbf{I}=\{(k, 1), \ldots,(K, M)\}$, $\mathbf{I}_{k}=\{(k, 1), \ldots,(k, M)\}$, and $\mathbf{I}_{m}=\{(1, m), \ldots,(K, m)\}$. For the sake of simplicity, we replace $k i$ with $(k, i)$ and assume that the geographical/economic features of the zone $i=(k, m)=k m$ can be specified as $e_{i}=e_{(k, m)}=e_{m}$ and $E_{i}=E_{(k, m)}=E_{m}$ for all $i$.

On the basis of urban economics, the utility maximization of a household is formalized as

$$
\begin{gathered}
V_{k m}=V\left(R_{k m}, e_{m}, E_{m}, \alpha_{k}, Y_{k}\right)=\max _{z_{k m}, q_{k m}} u\left(z_{k m}, q_{k m}, e_{m}, E_{m}, \alpha_{k}, Y_{k}\right) \\
\text { s.t. } \quad z_{k m}+R_{k m} q_{k m}=Y_{k m} .
\end{gathered}
$$

where $V(\cdot)$ is the indirect utility function, $u(\cdot)$ is the direct utility function, and $z$ is the consumption of the composite goods. The maximization yields to the individual demand function for building space (land in the original RURBAN model) as

$$
q_{k m}=q^{V}\left(R_{k m}, e_{m}, E_{m}, \alpha_{k}, Y_{k}\right)
$$

The bid rent function in urban economics is derived from the following maximizing problem.

$$
\begin{gathered}
B_{k m}=B\left(V_{k m}, e_{m}, E_{m}, \alpha_{k}, Y_{k}\right)=\max _{z_{k m}, q_{k m}}\left(Y_{k}-z_{k m}\right) / q_{k m} \\
u\left(z_{k m}, q_{k m}, e_{m}, E_{m}, \alpha_{k}, Y_{k}\right)=V_{k m}
\end{gathered}
$$


The maximization of the rent also yields to the individual demand for building.

$$
q_{k m}=q^{B}\left(V_{k m}, e_{m}, E_{m}, \alpha_{k}, Y_{k}\right) .
$$

Since the bid rent maximization stated in (A4) and (A5) is mutually consistent with the utility maximization in (A1) and (A2), the following conditions must hold.

$$
\begin{aligned}
& q^{B}\left(V_{k m}\left(R_{k m}, e_{m}, E_{m}, \alpha_{k}, Y_{k}\right), e_{m}, E_{m}, \alpha_{k}, Y_{k}\right)=q^{V}\left(R_{k m}, e_{m}, E_{m}, \alpha_{k}, Y_{k}\right), \\
& \text { and } q^{V}\left(B_{k m}\left(V_{k m}, e_{m}, E_{m}, \alpha_{k}, Y_{k}\right), e_{m}, E_{m}, \alpha_{k}, Y_{k}\right)=q^{B}\left(V_{k m}, e_{m}, E_{m}, \alpha_{k}, Y_{k}\right) .
\end{aligned}
$$

In an equilibrium state, the original RURBAN model defined the building (land) rent in the equilibrium state that appears in the indirect utility function as

$$
R_{m}^{*}=\left(\frac{1}{\gamma}\right) \ln \left\{\sum_{k \in \mathbf{K}} \exp \left(\gamma B_{k m}\right)\right\} \in \mathbf{R}_{+} .
$$

In contrast, the indirect utility that appears in the bid rent function is also defined in the log-sum form as

$$
V_{k}^{*}=\left(\frac{1}{\theta_{k}}\right) \ln \left\{\sum_{m \in \mathbf{M}} \exp \left(\theta_{k} V_{k m}\right)\right\} \in \mathbf{R} .
$$

In (A9) and (A10), * denotes the equilibrium. However, the original RURBAN model defined the indirect utility and the bid rent functions as

$$
\begin{aligned}
V_{k m} & =V\left(R_{m}^{*}, e_{m}, E_{m}, \alpha_{k}, Y_{k}\right) \neq V\left(R_{k m}, e_{m}, E_{m}, \alpha_{k}, Y_{k}\right), \\
\text { and } B_{k m} & =B\left(V_{k}^{*}, e_{m}, E_{m}, \alpha_{k}, Y_{k}\right) \neq B\left(V_{k m}, e_{m}, E_{m}, \alpha_{k}, Y_{k}\right) .
\end{aligned}
$$

Considering (A7) and (A8) with (A11) and (A12), we obtain

$$
q^{B}\left(V_{k}^{*}, e_{m}, E_{m}, \alpha_{k}, Y_{k}\right) \neq q^{V}\left(R_{m}^{*}, e_{m}, E_{m}, \alpha_{k}, Y_{k}\right)
$$

Therefore, the original RURBAN model was not successful in consistently formalizing the individual demand for building space since (A7) and (A8) were violated.

Restrictions on parameters in the random biding model and the random utility model stated in (A9) and (A10), respectively, were proposed in the original RURBAN model. On the basis of the notations used in this paper, the restrictions seem to be $\theta_{k} \rho_{k}=\gamma$ for all $k \in \mathbf{K}$ and $m \in \mathbf{M}$, where $\rho_{k}$ is the parameter associated with the bid rent. The restrictions on these parameters bridged the locator's and the landowner's behaviors in an ad hoc manner. Locators (demand side) and landowners (supply side) behave independently but interactively through price information in the land markets. The restrictions on the parameters thus violated a fundamental principle of the market 
equilibrium model. The original RURBAN model was not able to assess the sharing of the benefit of an urban policy explained in this paper.

The above inconsistency is the reason why we reformulated the RURBAN model in this paper.

\section{References}

Alonso W (1964) Location and land use. Harvard University Press, Cambridge, MA

Anas A (1982) Residential location markets and urban transportation. Academic Press, New York, NY

Anas A (1987) Modeling in urban and regional economics. Fundamentals of pure and applied economics, vol 26. Harwood Academic Publishers, London

Anas A, Liu Y (2007) A regional economy, land use, and transportation model (REULU-TRAN): formulation, algorithm design, and testing. J Reg Sci 47:415-455

Foot D (1981) Operational urban models: an introduction. Methuen, New York

Fujita M (1989) Urban economic theory. Cambridge University Press, Cambridge, MA

Hayashi Y, Doi K (1989) A model for analysing the imputation of commuters' benefits to land property values. In: Selected proceedings of the 5th world conference on transport research, pp 303-317

Hayashi Y, Tomita Y (1989) A micro-analytic residential mobility model for assessing the effects of transport improvement. In: Selected proceedings of the 5th world conference on transport research, pp 91-105

Herbert JS, Stevens BH (1960) A model of the distribution of residential activity in urban areas. J Reg Sci 2:21-36

Kim TJ (1989) Integrated urban systems modeling: theory and applications. Kluwer, Dordrecht

Lowry IS (1964) A model of metropolis. RM-4035-RC. Rand Corporation, Santa Monica, CA

Mills ES (1967) An aggregative model of resource allocation in a metropolitan area. Am Econ Rev 57: $197-210$

Mills ES (1972) Studies in the structure of the urban economy. John Hopkins Press, Baltimore

Miyagi T (1986) On the formulation of a stochastic user equilibrium model consistent with the random utility theory - a conjugate dual approach. In: Proceedings of the 4th world conference on transport research, vol 2, pp 1619-1635

Miyamoto K, Kitazume K (1990) A land use model based on random utility/rent-bidding analysis (RURBAN). In: Selected proceedings of the 5th world conference on transport research, vol 4, pp 107-121

Miyamoto K, Noami T, Kuwata Y, Yokozawa K (1993) An evaluation method of transport projects with the aid of RURBAN model, In: Selected proceedings of the 6th world conference on transport research, vol 1, pp 55-66

Miyamoto K, Vichiensan V, Sugiki N, Kitazume K (2007) Applications of RURBAN integrated with a transport model in detailed zone system. In: Proceedings of the 11th world conference on transport research, CD-ROM

Morisugi H, Ohno E (1992) A benefit incidence matrix for urban transport improvement. Pap Reg Sci J RSAI 71(1):53-70

Morisugi H, Ohno E, Miyagi T (1993) Benefit incidence of urban ring road - theory and case study of the Gifu ring road. Transportation 20:285-303

Muto S, Takagi A, Ueda T (2003) The benefit evaluation of transport network improvement with computable urban economic model. In: Selected proceedings of the 9th world conference on transport research, Elsevier Science, CD-ROM, No. 6218

Muto S, Ueda T, Yamaguchi K, Yamasaki K (2004) Evaluation of environmental pollutions occurred by transport infrastructure project at Tokyo metropolitan area. In: Selected proceedings of the 10th world conference on transport research, CD-ROM, No. 1152

Muth RF (1969) Cities and housing. University of Chicago Press, Chicago, IL

Oppenheim N (1995) Urban travel demand modeling: from individual choices to general equilibrium. Wiley, New York, NY

Shoven JB, Whalley W (1992) Applying general equilibrium. Cambridge University Press, Cambridge, MA 
Takagi A, Ueda T (2001) Evaluation of flood mitigation countermeasures considering the interdependence between flood risk and land use. First annual IIASA-DPRI meeting 2001. Available: http://www.iiasa. ac.at/Research/RMS/dpri2001/paper_pdf/papers.html. Accessed 20 Aug 2010

Takagi A, Muto S, Ueda T (1999) The benefit evaluation of urban transportation improvements with computable urban economic model. In: '99 Shanghai international symposium on urban transportation proceedings, pp 87-99

Ueda T, Hiratani K, Tsutsumi M (1993) Landuse model based on the general equilibrium of land and building markets. In: Proceedings of international conference on land problem and urban policy, Kyoto, pp 183-198

Ueda T, Tsutsumi M, Nakamura H (1995) An urban transport and activity location model for the evaluation of commuting rail improvement, presented at the 7 th world conference of transportation research, Sydney, Australia, 16-21 July 1995. Available: http://surveyor.sk.tsukuba.ac.jp/paper/7th_wctr.pdf. Accessed 20 Aug 2010

Vairan HR (1992) Microeconomic analysis, 3rd edn. Norton, New York, NY

Webster FV, Bly PH, Paulley NJ (eds) (1988) Urban land-use and transport interaction, policies and models. Gower Publishing Company Ltd, Avebury

Wegener M (2003) Overview of land-use transport models. In: Proceedings of CUPUM '03 Sendai (conference brochure of CUPUM '03 Sendai), pp 20-40

Yamasaki K, Ueda T, Muto S (2007) The evaluation of the Tokyo-metropolitan area policy by computable urban economic model (CUE). In: Selected proceedings of the 11th world conference on transport research, University of California, Berkeley, CD-ROM, No. 734

Yamasaki K, Ueda T, Muto S (2008) Impacts of transport infrastructure policies in population-declining metropolitan area-business productivity and quality of urban life in tokyo, presented at 11 th Uddevalla symposium 2008, Kyoto, Japan

Yoon JJ, Aoyama Y, Nakagawa D, Matsunaka R (2000) A practical land use-transport interaction model considering changes in population and industrial activities. In: Proceedings of international symposium on city planning 2000, Kobe, Japan, pp 381-390

Yoon JJ, Aoyama Y, Nakagawa D, Matsunaka R (2003) An evaluation of urban and transport policy using a land-use/transport interaction model, In: Selected proceedings of the 9 th world conference on transport research, CD-ROM, No. 6114 